\title{
STEM: Customized for Them
}

\section{Mrs. Laine Schrewe, Tolles Career and Technical Center}

Laine Schrewe has been an engineering instructor for Tolles Career and Technical Center with a satellite classroom in Jonathan Alder High School (Plain City, Ohio) for three years. Before becoming a teacher, Laine was an engine design engineer for Honda R\&D of America for nine years and has a Bachelor's (from the Cooper Union for the Advancement of Science and Art; New York, New York) and Master's degree (from the University of Wisconsin - Madison) in Mechanical Engineering. She is currently obtaining a Master of Arts degree in Workforce Development (from the Ohio State University). 


\section{S $\downarrow^{\dagger}$ EM: Customized for Them How to attract students toward education's latest trend}

Bringing STEM (Science, Technology, Engineering and Mathematics) into the classroom is the latest craze in educational strategies. And what is more trendy in education than STEM initiatives? Well, pretty much the same thing, but with special guest letters like STEAM (+ Art) and STREAM (+ Reading). Acronyms aside, STEM courses are still a tough sell for a lot of students who don't excel in the traditional math and science courses. Tailoring our curriculums and course offerings toward these science-y initiatives is only effective if you can get students excited about taking these courses. This means that finding a way to break down wary students' preconceived ideas about what these STEM-based courses will entail and getting them intrigued and excited about these courses is critical in establishing a successful STEM-based strategy in a school. This paper discusses how student feedback was used to promote and grow an engineering program at the high school level.

Tolles Career and Technical Center partnered with Jonathan Alder School District to create two STEM-based pathways that could feed into the career center in the district: (1) Engineering and (2) Information Technology. Jonathan Alder High School, located in rural Plain City, Ohio with a student population of around 650 students in 9-12th grades, is located just minutes from Tolles and is one of many satellite schools the technical center serves. The engineering program began in the 2015-2016 school year with one course offering: Engineering Design. The enrollment for this program was 41 students ranging from 9th to 12th grades. For the second year of the program, two courses were offered: Engineering Design and Mechanisms and Drives. The total program enrollment for the second year was 47 students. Looking at these first two pilot years, program enrollment was relatively steady despite increased course offerings, and some of the smaller classes seemed to suffer due to low class size and the subsequent limited ideas that were produced in that environment. Another factor that seemed critical in the production of original ideas was gender diversity. Classes with a more even ratio of males to females had notably more engaging discussions and a wider range of ideas than classes that were all one gender.

Looking at the 2016-2017 enrollment specifically, classes (50-minutes each) ranged anywhere from 6 - 14 students per class and were predominantly male. As discussed previously, classes that were on the lower end of the enrollment spectrum (in both population and diversity) yielded limited discussion, pairings/groupings, and original ideas. Based on the classes with the most success in the first two years of the program, the goal for an "ideal" class size was set at 12-14 students in order to optimally balance one-on-one student-teacher interaction and group discussion. (Success here is measured as a function of class atmosphere generated by student outgoingness, willingness to share ideas, grades and ability to absorb a student who may have a negative outlook on the class without the entire class atmosphere being impacted.) One 
additional goal for the program was to increase gender diversity above the current workforce ratio of $15 \%$ female engineers ${ }^{1}$ (a statistic that matches the average female student ratio in this engineering program through the end of the 2016-2017 academic year).

In an effort to work toward achieving these goals, a survey was sent out to the entire high school student population to gauge what aspects of STEM were the most enticing, interesting, or - for some - at least palatable. Out of the $\sim 650$ students enrolled, $50 \%$ (375) responses were obtained from the student body, which is a result that can be analyzed with $99 \%$ confidence ${ }^{2}$. The overall goal of the survey was to find ways to restructure the engineering program and the curriculums within the program to better serve the student body population and their interests. Questions ranged from personal interest in STEM to extracurricular involvement to ranking interest in different categories related to STEM subjects. Key findings from this survey are discussed below.

Overall, student interest in STEM courses (for both male and female students) seems to remain relatively constant over one's high school career - meaning that freshmen don't have significantly more enthusiasm for these subjects than seniors, or vice versa. When asked if students were interested in STEM courses (in general), $80 \%$ of male students answered that they have some interest in STEM courses, compared to only $60 \%$ of female students.

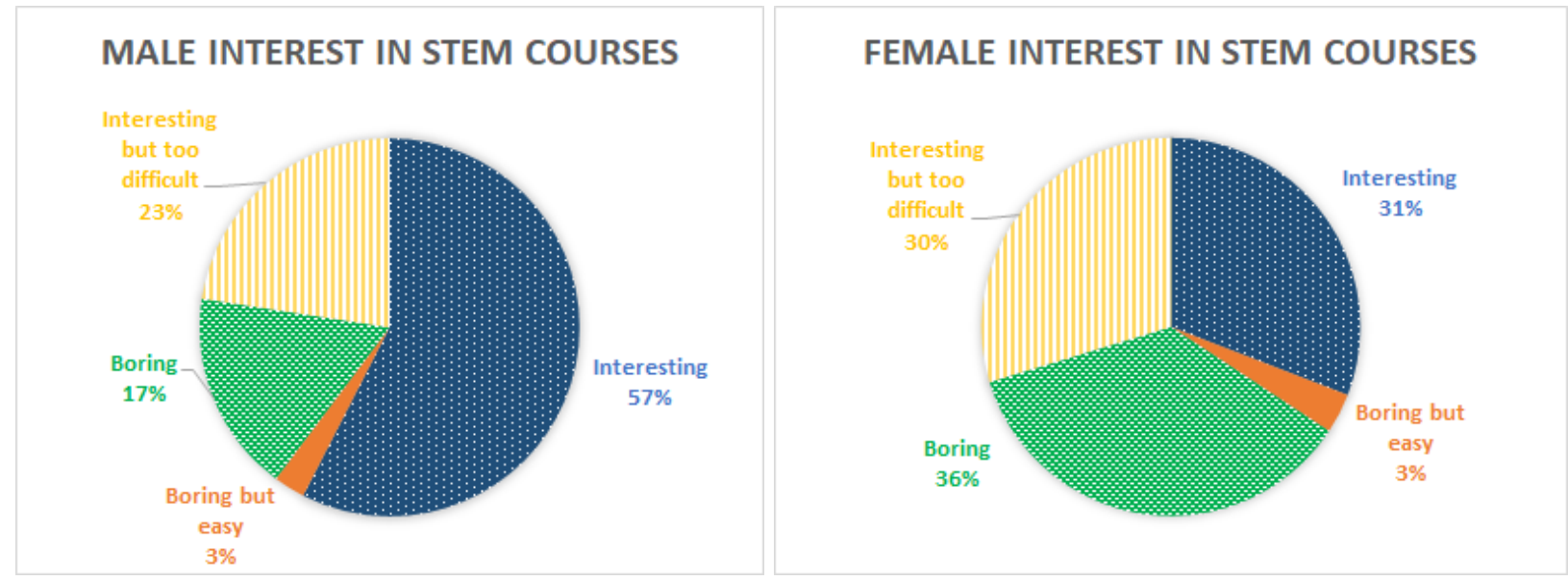

Charts 1a and 1b: Data for male and female responders related to the following survey question:

Please select which of the following BEST describes how you feel about STEM-related electives (such as Engineering, Computer Hardware, etc.)

a. Those classes sound interesting.

b. Those classes sound pretty interesting, but I don't think I'm smart enough to do well in them.

c. Those classes sound pretty boring.

d. Those classes sound pretty boring, but they are probably easy.

And, of the students who said they are interested in STEM courses, half of females believe they are not smart enough to do well in a STEM elective, while only a third of males had that concern 
(Chart 1a and 1b). This data clearly supports the ongoing gender gap seen in STEM fields, and highlights the need to find a way not only to increase the spark of interest for a wider range of students, but to help them build confidence in their ability to succeed in these areas as well.

The current courses were named to match the Ohio Department of Education standards that were set for each course. Unfortunately, these course titles may not only be intimidating or uninteresting to students - they also may not accurately represent the content of the course as it would be seen from a high school student's perspective. The Engineering Design course title seems fairly representative of the content it explores. It discusses how ideas are turned into design and most students are able to conceptualize what might take place in a design-based class. Mechanisms and Drives, however, is a very abstract concept/title for students to emotionally attach to, even though the class is strongly based on robotics (building, programming, and understanding how the components work), which is a topic that most people can identify with in the current technological climate. Creating a third course in the program related to the Manufacturing Operations standards is also an option, and if introduced, determining the best way to badge that course to promote not only increased enrollment but increased diversity is crucial. These are the ideas and concepts that the remainder of the survey questions were posed to address.

The Engineering Design course has relatively steady enrollment and the course title and content theme seems easy for students to be excited about. Therefore, the survey did not aim to modify this course or its title. However, given several options, the survey showed that students would find the current Mechanisms and Drives class three times more enticing if it were renamed as Robotics (Chart 2).

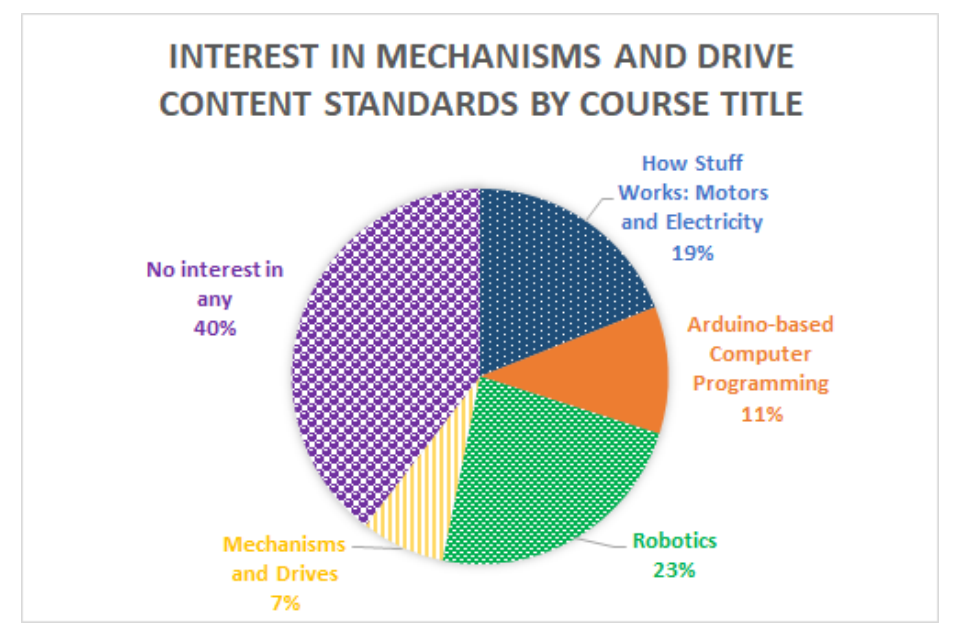

\section{Chart 2: Data for all responders related to the following survey question:}

Survey question used to generate this data: Which of these classes would you be most interested in taking?

a. Robotics

b. Arduino-based Computer Programming

c. How Stuff Works: Motors and Electricity

d. Mechanisms and Drives

e. None of these sound even remotely interesting to me.

The data shows that enrollment in Mechanisms and Drives should triple if renamed as a Robotics class. 
When given multiple options for a theme in a manufacturing class, clear front runners for course content topics became visible.
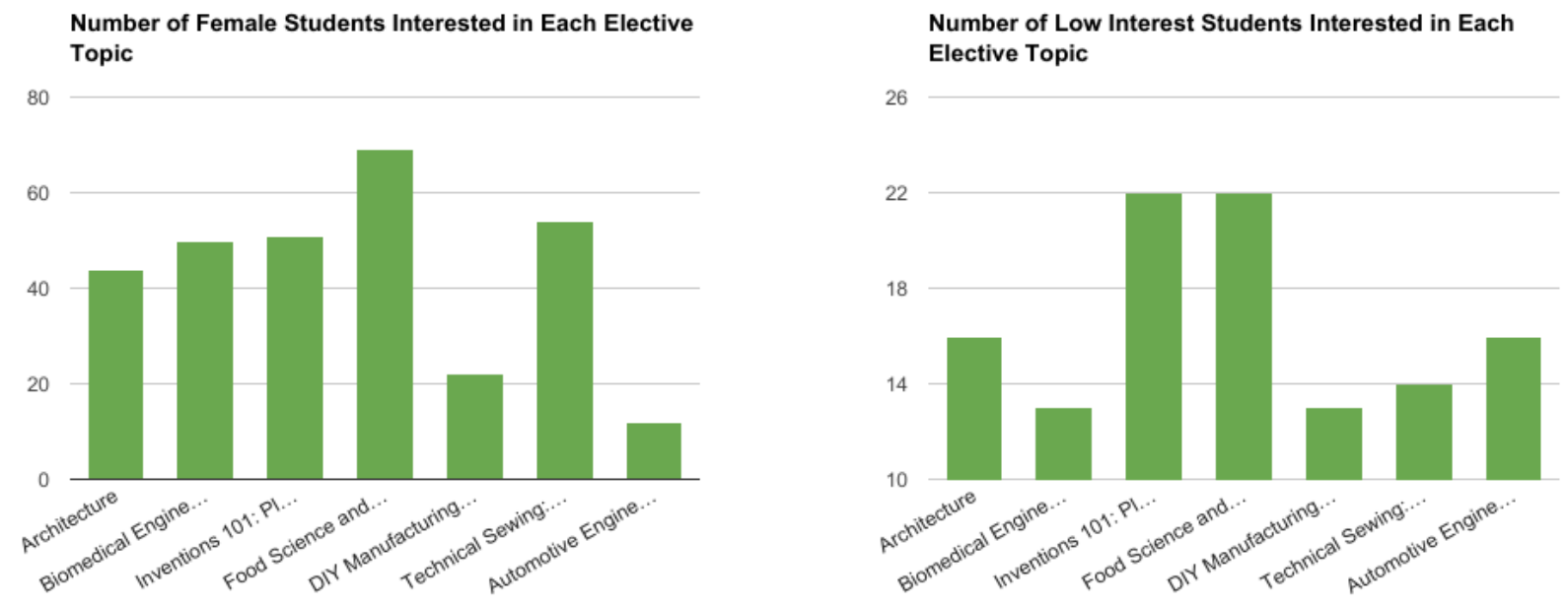

Charts 3a and 3b: Data for female and low interest responders related to the following survey question:

Survey questions used to generate this data: Which of the following STEM elective classes would you like to take?

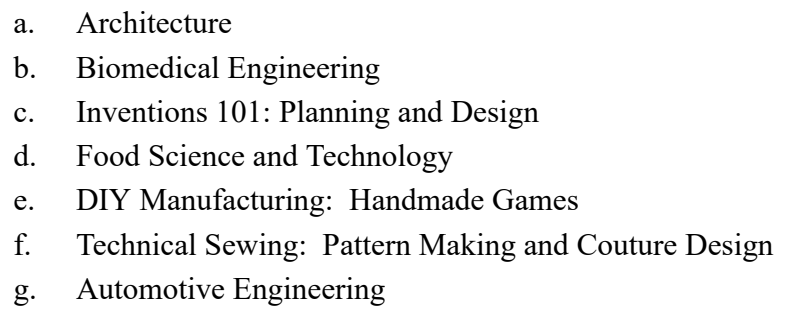

Manufacturing can be seen in almost any industry in any field, so building a curriculum around the topic most interesting to students seems like an obvious starting point for building a successful manufacturing-based engineering course offering. When seven diverse topics were introduced to students, the survey data showed that students would be most interested in a new engineering course if it was related to food, innovation/inventions or architecture (Charts $3 \mathrm{a}$ and $3 b)$. When broken down even further, creating a class about Inventions or Food Science would be the most appealing to students who do not think STEM subjects in general are interesting, including females. Therefore, Food Engineering would be the most beneficial class extension to increase enrollment of females, those not traditionally interested in STEM courses, and overall student population.

To summarize, the results of the survey suggest that the program would see optimal enrollment if the following three courses (shown with the related content standard titles) were offered:

$>$ Engineering Design (Engineering Design)

$>$ Robotics (Mechanisms and Drives)

$>$ Food Engineering (Manufacturing Operations) 
This course lineup was included in the course handbook for the next school year (2017-2018) and the results of student course selection / enrollment as compared to previous years are shown below.

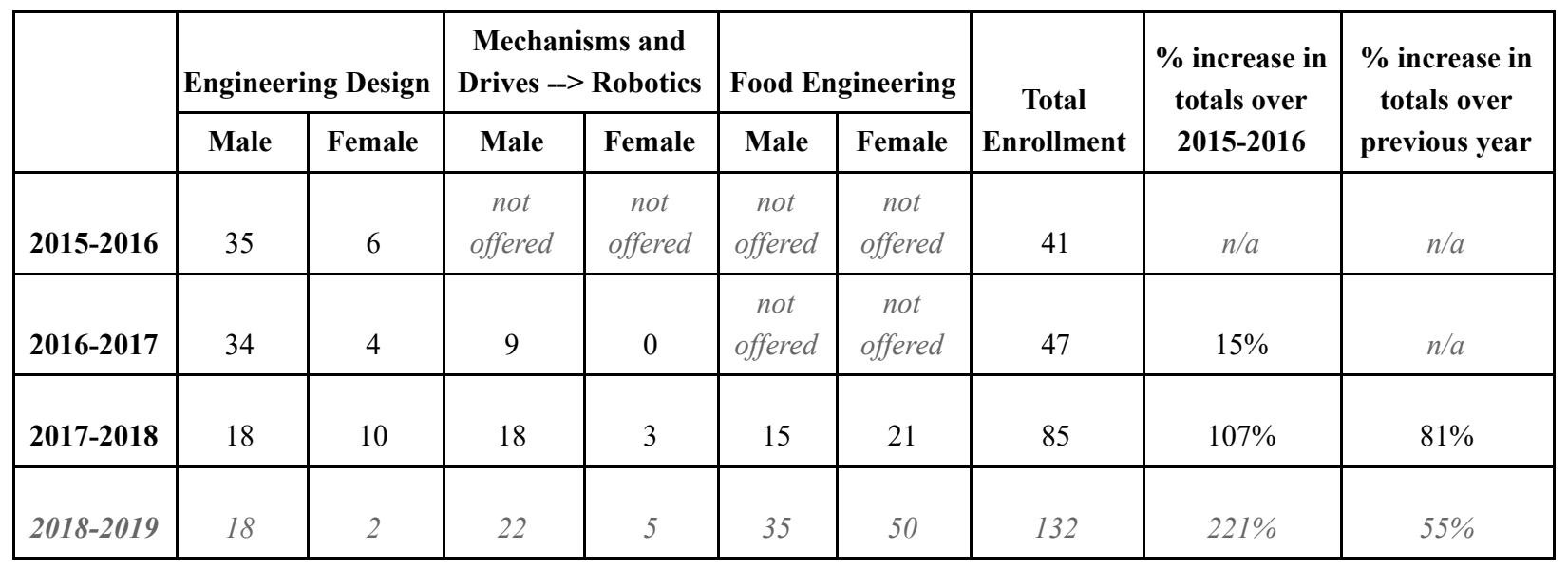

Table 1: Enrollment Data

The validity of the survey results is revealed through the 2017-2018 enrollment data. The survey results predicted that the Mechanisms and Drives content standards driven class could triple in enrollment if renamed as Robotics and the actual enrollment data nearly supports that result with an increase of nearly 2.5 times previous enrollment. Survey data also predicted that enrollment of female students and students not interested in traditional STEM courses could be boosted with a food-themed course, which is also supported with the 2017-2018 enrollment data. Female program enrollment is up from $8.5 \%^{3}$ to $40 \%$ and overall program enrollment is up by $81 \%$ over the previous academic year. With this new enrollment, class sizes should average at around 14 students, which achieves the goal set for the program. And, at $40 \%$ female enrollment, the target to achieve numbers higher than the workforce average of $15 \%$ was nearly tripled.

Preliminary 2018-2019 enrollment confirms these trends. For Robotics, enrollment data exactly matches the survey data predictions with 27 students enrolled (triple the 2016-2017 population). Enrollment in Food Engineering has skyrocketed for all grades, with 85 students signed up for this course. Finally, of the overall 132 students $(\sim 20 \%$ of the student body) requesting and engineering course for the 2018-2019 school year, approximately $40 \%$ are female - which reconfirms the previous year's target-exceeding result.

After taking part in their selected courses, students were again surveyed to understand their experience and impression of the engineering course they had taken in an effort to gauge whether or not the redesigned course offering changes were causing people to sign up for something that they ultimately would not find enjoyable, or would feel as if they were tricked into by a catchy title. Overall, results showed that almost $80 \%$ of students held a positive feeling about the class - 
whether it was due to general interest in engineering or their improved confidence in the area (Chart 4). And when the data is analyzed to look at female students only, the same trend holds true. $40 \%$ of female students say they used to think engineering concepts were too difficult, but

\section{STUDENT VIEW OF ENGINEERING AFTER TAKING THE COURSE}

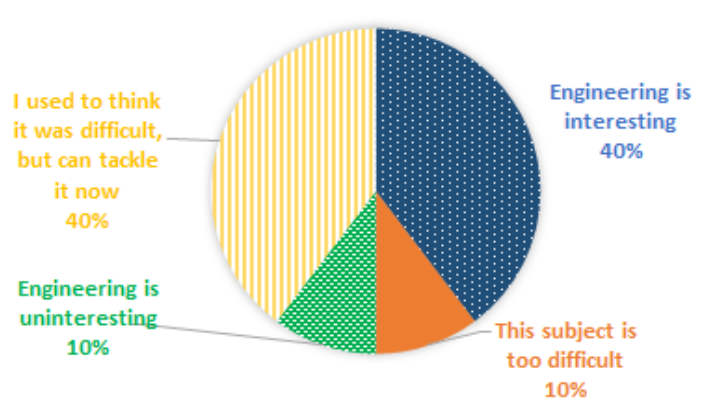
now they feel like it is something they are capable of. And since our pre-course survey showed that half of females did not feel "smart enough" for this field, this $40 \%$ improvement in academic confidence is clearly a trend we need to to continue to strive for to improve female participation in the STEM fields that have long been markedly male-dominated.

Chart 4: Data from enrolled students after completing one semester of the course.

Survey questions used to generate this data: How has this course shaped your view of engineering in general?

a. I really enjoy engineering and this class has solidified that feeling.

b. I used to think engineering was too difficult for me, but now feel like it is something I am capable of.

c. I thought I would like engineering, but after taking this class realize it is too difficult for me.

d. I thought I would like engineering, buy after taking this class I realize I find it uninteresting.

Getting student feedback can be an invaluable tool to use when recruiting for and refining a program, regardless of the content area. Admittedly this specific engineering program is still in its infancy and enrollment may be skewed due to increased program visibility and word of mouth as more and more students experience the program and an understanding of what to expect from the course becomes more common knowledge throughout the student body. But regardless, the accuracy of the survey in predicting and improving the actual enrollment condition should not be diminished. Using this tool at the beginning of a program, when it needs to be reinvented, or as a scheduled maintenance check for your program's relevance is beneficial to make sure courses are well aligned with the interests of the students it serves.

Paper authored and researched ${ }^{4}$ by Laine Schrewe, engineering instructor for Tolles Career and Technical Center located in Jonathan Alder High School, Plain City, Ohio ; March, 2018.

Notes:

1. Source: National Girls Collaborative project; https://ngcproject.org/statistics ( $15 \%$ of engineers are women)

2. Claims extrapolated from sample size guidelines table data from https://www.surveymonkey.com/mp/sample-size/

3. Female enrollment data from 2016-2017 school year

4. Initial survey completed during the fall of the 2016-2017 school year. Second survey was performed after the completion of the first semester of the 2017-2018 school year. 